\title{
Diferenças entre os sexos no ciúme romântico: um estudo brasileiro
}

\author{
Sex Differences in Romantic Jealousy: A Brazilian Study \\ Diferencias entre los sexos en celos románticos: un estudio brasilero
}

\author{
Lucas de Francisco Carvalho, ${ }^{*}$ Rodolfo A. M. Ambiel* \\ Universidade São Francisco, Brasil.
}

Doi: dx.doi.org/10.12804/apl34.1.2016.10

\section{Resumo}

A literatura sobre ciúme romântico aponta duas propostas teóricas principais em relação as diferenças entre os sexos: módulo inato específico e teoria sócio-cognitiva, cada uma com metodologia de avaliação. Este estudo pretendeu comparar respostas de homens e mulheres usando um questionário em formato de escolha forçada e, o mesmo questionário, na forma de mensuração contínua. Participaram 378 estudantes, divididos em dois grupos que responderam ao questionário nos diferentes formatos. As diferenças entre os sexos só foram evidentes no grupo 1 e pouca diferença foi encontrada comparando-se crenças de homens e mulheres quanto à infidelidade e à relação romântica, nos dois grupos. Evidencia-se a necessidade de mais estudos sobre o tema. Palavras chave: ciúme; gênero; avaliação psicológica.

\section{Abstract}

The literature about romantic jealousy shows two principal theories in relation to the differences between sexes: specific innate module and socio-cognitive theory. This study intended to compare men and women answers using a questionnaire in the format of forced choice and the same questionnaire in the format of continuous measurement. 378 students participated, divided into two groups that answered the questionnaire in different formats. The differences between sexes was only evidenced on group 1 and few differences were found comparing men and women beliefs about infidelity and romantic relationship, on both groups. We pointed out the need for more studies in this field.

Keywords: jealousy; gender; psychological assessment.

\section{Resumen}

La teoría sobre celos románticos apunta a dos propuestas teóricas principales en relación con las diferencias entre los sexos: módulo innato específico y teoría sociocognitiva, cada una con su metodología de evaluación. Este estudio se propuso comparar respuestas de hombres y mujeres usando un cuestionario de selección forzada y el mismo cuestionario pero con medición continua. Par-

* Lucas de Francisco Carvalho, Programa de Pós-Graduação Stricto Sensu em Psicologia, Universidade São Francisco, Itatiba-SP, Brasil. Rodolfo A. M. Ambiel, Programa de Pós-Graduação Stricto Sensu em Psicologia, Universidade São Francisco, Itatiba-SP, Brasil.

A correspondência deste artigo pode se dirigir a Lucas de Francisco Carvalho, Universidade São Francisco, Rua Alexandre Rodrigues Barbosa, 45 CEP 13251-900, Itatiba, São Paulo, Brasil. Correio eletrônico: lucas@labape.com.br

Como citar este artigo: Carvalho, L. de F. \& Ambiel, R. A. M. (2016). Diferenças entre os sexos no ciúme romântico: um estudo brasileiro. Avances en Psicología Latinoamericana, 34(1), 143-155. doi: dx.doi.org/10.12804/apl34.1.2016.10 
ticiparon 378 estudiantes, divididos en dos grupos que respondieron el cuestionario en los diferentes formatos. Las diferencias entre los sexos solo se evidenciaron en el grupo 1 y se encontraron pocas diferencias al comparar creencias de hombres y mujeres respecto a la infidelidad y la relación romántica. Se identificó la necesidad de más estudios sobre el tema.

Palabras clave: celos; género; evaluación psicológica.

O ciúme é citado na literatura há séculos, por exemplo, o Antigo Testamento da Bíblia (Harris, 2005). Ao mesmo tempo em que visa proteger o relacionamento, o ciúme é capaz de destruí-lo (Ramos \& Calegaro, 2001), sendo uma reação comumente expressa no cotidiano. O ciúme pode ser expresso em diferentes contextos, e especificamente em relacionamentos românticos ou amorosos, em que é nomeado de ciúme romântico, pode ser entendido como um conjunto de reações frente à ameaça de um rival (real ou não) a um relacionamento amoroso (Buss, Larsen \& Westen, 1996; Kingham \& Gordon, 2004). Apesar do ciúme romântico estar presente na vida das pessoas de modo geral, os dados sugerem que as mulheres apresentam mais ciúme que os homens, o que caracteriza uma diferença na ocorrência do ciúme entre os sexos (Mullen \& Martin, 1994; Sagarin \& Guadagno, 2004).

Segundo Harris e Christenfeld (1996a), as diferenças psicológicas entre homens e mulheres têm origem na diferenciação genética, apesar de não haver consenso na literatura sobre como os sexos se distinguem em relação ao ciúme romântico. Os resultados provindos de estudos são por vezes contraditórios, sendo um dos poucos pontos mais próximos de um consenso, a mulher frequentemente apresentar mais reações de ciúme romântico, no que diz respeito à intensidade e frequência, em comparação ao homem (DeSteno \& Salovey, 1996; Harris, 2005; Sagarin, 2005; Shackelford, Buss \& Bennett, 2002).
Por um lado, pesquisas com relação à diferença entre os sexos mostram-se como um dos campos mais estudados na área (Harris \& Christenfeld, 1996b; Harris, 2003a; Harris, 2003b; DeSteno, Barlett, Braverman \& Salovey, 2002). Por outro, no Brasil, a diferença de gênero em relação com o ciúme romântico é um tema ainda pouco explorado, com um número escasso de dados empíricos (por exemplo, Ades, 2003). Esta constatação corrobora o que Costa (2005) e Leite (2001) afirmaram a respeito da escassez de estudos sobre ciúme no país. Diferentemente, teóricos de outros países, a partir de estudos empíricos, descrevem diferentes teorias para explicar o mecanismo do ciúme romântico e possíveis semelhanças e diferenças deste mecanismo entre os sexos.

São duas as teorias mais frequentemente citadas no que diz respeito à diferença entre os sexos em relação ao ciúme romântico: psicologia evolutiva e psicologia sócio-cognitiva. Por parte dos psicólogos evolutivos, a formulação é chamada de Jealousy as a Specific Innate Module (JSIM) (Harris, 2005; Shackelford et al., 2002). Enquanto que pelos teóricos da psicologia sócio-cognitiva, é denominada de Social Cognitive Theory of Jealousy (SCTJ) (Harris, 2003b). Ambas as perspectivas são apresentadas na sequência.

Partindo da história evolutiva da espécie humana, teóricos evolutivos descrevem padrões de comportamento distintos de acordo com o sexo. A mulher, enquanto geradora, tinha como uma das tarefas básicas de seu cotidiano, cuidar da prole. Neste contexto, um homem que assegurasse a sobrevivência de seus filhos e, dela própria, era essencial. Ao homem cabia, então, a função de proteger e alimentar a mulher e a prole (Buss, Larsen, Westen \& Semmelroth, 1992; Buss, Larsen \& Westen, 1996).

De um lado, o ciúme romântico estrutura-se enquanto um mecanismo sinalizador à mulher de uma situação de risco de perder o homem que lhe garante os recursos necessários à sobrevivência. Por isso, segundo a JSIM, a mulher preocupa-se 
mais com a infidelidade emocional do parceiro, ou seja, o parceiro relacionar-se afetivamente com outra mulher (como, por exemplo, comportamentos carinhosos do parceiro dirigidos à outra mulher). Por outro lado, para o homem, o ciúme romântico seria um mecanismo destinado a assegurar-lhe que a prole de sua parceira também é sua, uma vez que a garantia que a mulher tem dos filhos serem seus, a gravidez, não ocorre com o homem (Buss et al., 1992, 1996). Desse modo, a JSIM propõe que os homens se preocupam mais com a infidelidade sexual da parceira, isto é, a parceira ter relações sexuais com outro homem.

Segundo Buss et al. (1996), uma vez que o homem foi moldado durante a evolução de modo a estar mais preocupado com a infidelidade sexual de sua parceira, ele desenvolverá um mecanismo de ciúme voltado para sinais de infidelidade sexual: o ciúme sexual. No caso da mulher, por ter sido modelada evolutivamente de forma a preocupar-se com a infidelidade emocional, ela desenvolverá um mecanismo de ciúme direcionado para sinais de infidelidade amorosa: o ciúme amoroso (Buss et al., 1996).

O contexto descrito anteriormente, retratando um aspecto da evolução humana, é a base da proposição evolutiva sobre a diferença entre os sexos em relação ao ciúme romântico. Ainda que as diferenças entre homens e mulheres sejam explícitas nessa formulação, em ambos os sexos o ciúme romântico é entendido como um módulo, isto é, um mecanismo cognitivo inato designado para processar uma informação específica de maneira automática (DeSteno et al., 2002).

Em contrapartida à compreensão do ciúme romântico enquanto um módulo específico e inato, a teoria sócio-cognitiva do ciúme (SCTJ) se pauta, sobretudo, em aspectos sociais e processamento cognitivo e padrões de crenças e interpretações pessoais (Harris, 2003b; Harris, 2005). A maior ênfase desta teoria está na relevância das experiências de vida como variáveis de influência na manifestação do ciúme e nas crenças do indivíduo. ${ }^{1}$ Estas envolvem processamento de informação e são formadas durante a socialização (Harris, 2005). São dois os fatores, segundo a SCTJ, que podem ter maior impacto na experiência do ciúme romântico. $\mathrm{O}$ primeiro fator refere-se às crenças que estão envolvidas no relacionamento amoroso, e o segundo, a aspectos também cognitivos, sendo, o autoconceito, e a auto-estima, que são desafiados por um rival. Um rival refere-se a alguém ou até mesmo algo que sinalize a perda de um parceiro importante (Harris, 2005).

A SCTJ entende que a interpretação e a avaliação do indivíduo a respeito de ameaças ao relacionamento amoroso é um importante fator a ser investigado no ciúme, uma vez que é a partir da interpretação que o indivíduo reage ao mundo. Portanto, o ciúme estará presente quando o indivíduo interpretar que o relacionamento está ameaçado (Harris, 2003b). Isto significa que, para os teóricos da SCTJ, existe um mesmo processo básico em situações de ciúme em relacionamentos amorosos e em outras formas de relacionamentos (entre irmãos, por exemplo) (Harris, 2003b).

Desse modo, na SCTJ, o ciúme é entendido como um fenômeno construído ao longo da vida de cada indivíduo, que se diferencia no que diz respeito a sua manifestação (topografia do comportamento, intensidade e frequência das reações), de acordo com a experiência de vida de cada indivíduo, e não necessariamente varia de acordo com o sexo (Harris, 2005). Esta é uma das diferenças mais relevantes entre as duas teorias apresentadas. Enquanto a JSIM propõe a diferença entre os sexos na manifestação e função do ciúme, a SCTJ sugere uma diferença na manifestação do ciúme entre os indivíduos, mas não necessariamente entre os sexos uma vez que, nesta abordagem, o ciúme sexual ou

1 Decidiu-se manter o termo proposto pelos teóricos que utilizam esta teoria. Em uma linguagem analítico-comportamental, crenças, interpretações, concepções podem ser entendidas como auto-regras (Costa, 2002). 
amoroso, é entendido como um mecanismo sinalizador de ameaças a um relacionamento amoroso importante, para ambos os sexos, como aponta Harris (2005).

Partindo do mesmo raciocínio, de que a diferenciação no mecanismo do ciúme é individual, moldada por diferentes aprendizagens e interpretações dos fatos (crenças), e não necessariamente por gêneros diferentes, DeSteno e Salovey (1996) desenvolveram a hipótese double-shot (DS) ou do "tiro-duplo". Essa hipótese sugere uma diferença entre os sexos, não em termos de mecanismos específicos, mas de crenças entre homens e mulheres. Paralela a hipótese DS, Harris e Christenfeld (1996a) lançam a hipótese two-for-one ("dois para um"), contemplando o mesmo pressuposto e compreensão, mas com foco mais na infidelidade no que no ciúme por si. Verifica-se que ambas as propostas entendem que são as diferenças encontradas nas crenças dos indivíduos que explicam as diferenças entre os sexos, e não um mecanismo inato e especialmente diferenciado pelo gênero.

Segundo a DS (DeSteno \& Salovey, 1996; Harris \& Christenfeld, 1996b), para a mulher, o ciúme emocional aparece significantemente mais intenso em comparação ao ciúme por infidelidade sexual. E, para o homem, o ciúme sexual e o ciúme amoroso perturbam com intensidade muito similar, ainda que em diferentes estudos, ora o ciúme amoroso esteja mais presente, ora o sexual. Tal oscilação pode ser observada, por exemplo, em um estudo realizado por Buss et al. (1992), no qual homens e mulheres demonstraram mais ciúme sexual do que amoroso; e, também, em um estudo apresentado por Harris e Christenfeld (1996a), onde homens apresentaram mais ciúme frente à infidelidade emocional.

A explicação baseada na DS para tais resultados é que a diferença está em um raciocínio diferenciado, entre homens e mulheres, acerca da representação ou crença dos dois tipos de infidelidade (amorosa e sexual). Para a mulher, a infidelidade amorosa do homem, muito provavelmente, irá levar a uma infidelidade sexual ("se o homem amar, ele provavelmente terá relações sexuais”). Segundo Harris (2003a) o que ocorre é a crença de que os homens não precisam amar para ter relações sexuais, mas caso ele ame, irá ter relações sexuais. Assim, as mulheres apresentam, de modo bastante significativo, mais ciúme frente a situações de infidelidade amorosa, do que frente a situações de infidelidade sexual. E, para o homem, a infidelidade amorosa pode levar à infidelidade sexual, assim como a infidelidade sexual à amorosa ("se a mulher amar, ela terá relações sexuais em dado momento, e, se ela tiver relações sexuais, ela provavelmente está amando") (DeSteno \& Salovey, 1996). De um modo geral, os homens têm a crença de que se a mulher tiver relações sexuais com outro homem, de certo que ela ama este outro, e se ela estiver envolvida emocionalmente com outro homem, é provável que ela terá relações sexuais com ele (Harris, 2003a). Tais crenças fazem com que o ciúme no homem oscile entre amoroso e sexual (Harris \& Christenfeld, 1996a).

\section{Diferenças entre os sexos: alguns resultados de acordo com a JSIM e a SCTJ}

Para investigar a validade da hipótese da DS, assim como para testar a hipótese da JSIM, diversos estudos vêm sendo conduzidos. Contudo, a fim de verificar a consistência das hipóteses propostas, usualmente são utilizados dois formatos distintos de instrumentos: oforced-choice ("escolha forçada"), e o continues measures ("mensurações contínuas"). O uso de dois instrumentos distintos nas pesquisas tem resultado em diferentes dados acerca da diferença entre os sexos em relação ao ciúme romântico, como pode ser observado na tabela 1 . Ressalta-se que o presente estudo tem como foco testar diferenças decorrentes do formato avaliativo, partindo dos formatos tipicamente utilizado com base na DS e na JSIM. 
Tabela 1

Estudos com escolha forçada e mensurações contínuas

\begin{tabular}{|c|c|c|c|}
\hline Artigos & Estudos & Resultados & Formato \\
\hline $\begin{array}{l}\text { Buss et al. } \\
(1992)\end{array}$ & $\begin{array}{l}\text { Verificou qual ciúme é mais freqüente entre ho- } \\
\text { mens e mulheres - Escolha Forçada }\end{array}$ & $\begin{array}{l}\text { Homens apresentam mais ciúme sexual e } \\
\text { as mulheres mais ciúme amoroso }\end{array}$ & $\begin{array}{l}\text { Escolha } \\
\text { forçada }\end{array}$ \\
\hline \multirow{2}{*}{$\begin{array}{l}\text { Harris e } \\
\text { Christenfeld } \\
\text { (1996a) }\end{array}$} & $\begin{array}{l}\text { Verificou qual ciúme é mais freqüente entre ho- } \\
\text { mens e mulheres - Escolha Forçada }\end{array}$ & $\begin{array}{l}\text { Homens apresentam mais ciúme sexual e } \\
\text { as mulheres mais ciúme amoroso }\end{array}$ & \multirow{2}{*}{$\begin{array}{l}\text { Escolha } \\
\text { forçada }\end{array}$} \\
\hline & $\begin{array}{l}\text { Verificou qual a infidelidade implica na outra, } \\
\text { para homens e para mulheres }\end{array}$ & $\begin{array}{l}\text { A infidelidade emocional implica na infi- } \\
\text { delidade sexual }\end{array}$ & \\
\hline $\begin{array}{l}\text { DeSteno } \\
\text { e Salovey } \\
(1996)\end{array}$ & $\begin{array}{l}\text { Verificou qual ciúme é mais freqüente entre ho- } \\
\text { mens e mulheres - Escolha Forçada }\end{array}$ & $\begin{array}{l}\text { Homem apresenta ciúme sexual e emocio- } \\
\text { nal sem diferença significativa; e a mulher } \\
\text { apresenta mais ciúme emocional }\end{array}$ & $\begin{array}{l}\text { Escolha } \\
\text { forçada }\end{array}$ \\
\hline \multirow[b]{2}{*}{$\begin{array}{l}\text { Shackelford } \\
\text { et al. (2002) }\end{array}$} & $\begin{array}{l}\text { Verificou se homens e mulheres diferenciam em } \\
\text { perdoar ou terminar o relacionamento quando há } \\
\text { infidelidade - Escolha Forçada }\end{array}$ & $\begin{array}{l}\text { Os homens apresentam mais dificuldade } \\
\text { em perdoar a infidelidade sexual }\end{array}$ & \multirow[b]{2}{*}{$\begin{array}{l}\text { Escolha } \\
\text { forçada }\end{array}$} \\
\hline & $\begin{array}{l}\text { Verificou o que seria mais difícil de perdoar para } \\
\text { homens e mulheres, e o que seria mais provável } \\
\text { em fazê-los terminar o relacionamento - Escolha } \\
\text { Forçada }\end{array}$ & $\begin{array}{l}\text { Os homens apresentaram resultados equi- } \\
\text { librados entre infidelidade sexual e infi- } \\
\text { delidade emocional; e para as mulheres a } \\
\text { infidelidade amorosa seria pior }\end{array}$ & \\
\hline \multirow{3}{*}{$\begin{array}{l}\text { Harris } \\
(2003 a)\end{array}$} & $\begin{array}{l}\text { Verificou qual ciúme é mais freqüente entre ho- } \\
\text { mens e mulheres - Escolha Forçada }\end{array}$ & $\begin{array}{l}\text { Homens apresentam mais ciúme sexual e } \\
\text { as mulheres mais ciúme amoroso }\end{array}$ & \multirow{3}{*}{$\begin{array}{l}\text { Escolha } \\
\text { forçada e } \\
\text { mensurações } \\
\text { contínuas }\end{array}$} \\
\hline & $\begin{array}{l}\text { Verificou qual ciúme é mais freqüente entre ho- } \\
\text { mens e mulheres - Mensurações Contínuas }\end{array}$ & $\begin{array}{l}\text { Ambos os sexos apresentaram mais ciúme } \\
\text { sexual }\end{array}$ & \\
\hline & $\begin{array}{l}\text { Verificou qual ciúme é mais freqüente entre } \\
\text { homens e mulheres, a partir de infidelidade real - } \\
\text { Mensurações Contínuas }\end{array}$ & $\begin{array}{l}\text { Ambos os sexos apresentaram mais ciúme } \\
\text { emocional }\end{array}$ & \\
\hline \multirow{3}{*}{$\begin{array}{l}\text { DeSteno et al. } \\
(2002)\end{array}$} & $\begin{array}{l}\text { Verificou qual ciúme é mais freqüente entre ho- } \\
\text { mens e mulheres - Escolha Forçada }\end{array}$ & $\begin{array}{l}\text { Homens apresentam mais ciúme sexual e } \\
\text { as mulheres mais ciúme amoroso }\end{array}$ & \multirow{3}{*}{$\begin{array}{l}\text { Escolha } \\
\text { forçada e } \\
\text { mensurações } \\
\text { contínuas }\end{array}$} \\
\hline & $\begin{array}{l}\text { Verificou qual ciúme é mais freqüente entre ho- } \\
\text { mens e mulheres - Mensurações Contínuas }\end{array}$ & $\begin{array}{l}\text { Ambos os sexos apresentaram mais ciúme } \\
\text { sexual }\end{array}$ & \\
\hline & $\begin{array}{l}\text { Verificou qual ciúme é mais freqüente entre } \\
\text { homens e mulheres - Escolha Forçada com Cog- } \\
\text { nitive Load ("pressão cognitiva" - procedimento } \\
\text { que visa restringir os recursos cognitivos do su- } \\
\text { jeito no momento de responder o instrumento* }\end{array}$ & $\begin{array}{l}\text { Ambos os sexos apresentaram mais ciúme } \\
\text { sexual }\end{array}$ & \\
\hline \multirow[t]{2}{*}{ Ades $(2003)^{* *}$} & $\begin{array}{l}\text { Verificou se a diferença entre os sexos proposta } \\
\text { pelos evolucionistas seria identificada em uma } \\
\text { amostra de estudantes de São Paulo - Escolha } \\
\text { Forçada }\end{array}$ & $\begin{array}{l}\text { Homens apresentam mais ciúme sexual e } \\
\text { as mulheres mais ciúme amoroso }\end{array}$ & \multirow{2}{*}{$\begin{array}{l}\text { Escolha } \\
\text { forçada e } \\
\text { mensurações } \\
\text { contínuas }\end{array}$} \\
\hline & $\begin{array}{l}\text { Identificou possíveis reações diante da infidelida- } \\
\text { de sexual e emocional - Mensurações Contínuas. }\end{array}$ & $\begin{array}{l}\text { Não foram encontradas reações diferentes } \\
\text { considerando o tipo de infidelidade }\end{array}$ & \\
\hline
\end{tabular}

\footnotetext{
* No estudo desenvolvido por DeSteno et al. (2002), os autores denominaram de pressão cognitiva a situação na qual o indivíduo, antes de responder ao dilema sobre infidelidade sexual ou emocional, deveria lembrar uma seqüência de sete dígitos, tendo 10 segundos para descrever a seqüência de dígitos e responder ao dilema.

** O objetivo geral deste estudo, cujo questionário conteve quatro partes que visavam a objetivos específicos, foi testar a generalidade da hipótese evolucionista acerca da diferença entre os sexos.
} 
Pode-se observar que pelo menos em um dos estudos descritos em cada artigo foi utilizado o instrumento no formato de escolha forçada como meio de coletar os dados. Entre as diversas pesquisas feitas sobre o ciúme e a diferença entre os sexos, a primeira a utilizar a escolha forçada foi a de Buss et al. (1992), de modo que os estudos posteriores procuraram replicá-lo, ainda que, algumas vezes, uma replicação com alterações em determinados aspectos.

Os participantes do estudo de Buss et al. (1992) eram instruídos a pensar em um relacionamento amoroso que já haviam tido, que estavam tendo, ou que gostariam de ter. Então, deveriam responder a pergunta: o que seria pior? Para respondê-la, teriam que escolher entre (A) "imaginar seu parceiro tendo uma profunda relação amorosa com esta pessoa", ou (B) "imaginar seu parceiro tendo um intercurso sexual com esta pessoa". Posteriormente, deveriam imaginar, e responder o que seria pior, igualmente ao modelo anterior: (A) "imaginar seu parceiro tentando diferentes posições sexuais com outra pessoa", ou (B) "imaginar seu parceiro "morrendo de amor' por outra pessoa".

Assim, este instrumento caracteriza-se como um procedimento de escolha obrigatória entre duas possibilidades (como o próprio nome diz, trata-se de uma escolha forçada), pois os participantes devem escolher entre uma (A) ou outra (B) alternativa, não havendo possibilidade da escolha entre diferentes intensidades, e não mais de uma variável é analisada (por exemplo, o contexto das situações propostas), como apontam DeSteno e Salovey (1996). Além disso, o uso das perguntas desenvolvidas pelos autores no formato de escolha forçada vem sendo usado como respaldo para a hipótese DS. Frente a isso, um ataque maciço quanto ao uso do instrumento de escolha forçada foi lançado aos psicólogos evolucionistas (DeSteno et al., 2002; DeSteno \& Salovey, 1996; Harris, 2003a; Harris, 2003b; Harris \& Christenfeld, 1996a; Harris \& Christenfeld, 1996b).
Dos estudos realizados nos sete artigos apresentados na tabela 1 , nove utilizaram o instrumento escolha forçada, e entre estes, sete tinham como objetivo verificar qual o tipo de ciúme seria o mais frequente entre homens e mulheres. Os resultados mostram uma clara tendência da diferenciação entre os sexos quando o instrumento escolha forçada é empregado em seu formato clássico (proposto por Buss et al., 1992), no qual os homens apresentam mais ciúme sexual e as mulheres mais ciúme amoroso (Buss et al., 1992; DeSteno et al., 2002; Harris, 2003; Harris e Christenfeld, 1996a). Contudo, alguns estudos, utilizando a escolha forçada, encontraram resultados diferentes, nos quais os homens escolheram de forma equivalente tanto o ciúme sexual quanto o amoroso (DeSteno \& Salovey, 1996).

Uma das pesquisas de DeSteno et al. (2002) objetivou testar a confiabilidade do instrumento de escolha forçada, introduzindo uma nova variável - a pressão cognitiva (isto é, o sujeito deveria realizar uma tarefa paralela enquanto respondia o questionário), como descrito anteriormente. A hipótese seria que as restrições nos recursos cognitivos causadas pela pressão cognitiva suprimiriam a diferenciação entre os sexos na manifestação do ciúme, caracterizando o instrumento de escolha forçada como superficial. A partir do uso da pressão cognitiva, juntamente com a escolha forçada, verificou-se que ambos os sexos são mais propensos a escolher o ciúme sexual, eliminando a diferença entre os sexos.

Para flexibilizar as opções de escolha dos participantes durante as pesquisas e verificar a validade dos resultados encontrados a partir da escolha forçada, diferentes estudos fizeram uso do mesmo questionário no formato de mensuração contínua (Harris, 2004). Na tabela 1 são quatro os estudos que utilizaram esse formato para coleta. As chamadas mensurações contínuas consistem de instrumentos que utilizam avaliações por escalas likert, agree-desagree (concorda-descorda), entre outras (DeSteno et al., 2002). São avaliações que 
possibilitem ao participante optar entre diversas respostas, de modo a variar na intensidade e freqüência das mesmas.

Em contraposição aos resultados obtidos a partir da escolha forçada, com mensurações contínuas, as diferenças entre homens e mulheres desaparecem (DeSteno et al., 2002; Harris, 2003). O uso de mensurações contínuas também tem evidenciado que as diferenças entre os sexos tendem a ser observadas quando a infidelidade é hipotética e não real (Harris, 2002, 2003a), dando base para a hipótese JSIM.

Basicamente, os resultados se dividem pelo tipo de instrumento utilizado no estudo. Quando o instrumento escolhido é o de escolha forçada, os dados tendem a apresentar diferença entre homens e mulheres no que diz respeito ao ciúme sexual e amoroso. E, quando o instrumento empregado utiliza a mensuração contínua, os dados tendem a eliminar a diferença entre os sexos. A presente pesquisa tem como foco verificar possíveis diferenças decorrentes dos formatos utilizados pelas tradições DS e JSIM. O presente estudo teve como objetivo verificar diferenças entre homens e mulheres quanto ao ciúme romântico variariam, levando em consideração ambos os tipos de formatos para avaliação.

\section{Método}

\section{Participantes}

Participaram da pesquisa 378 universitários do curso de Psicologia de uma universidade particular da cidade de São Paulo, homens e mulheres, com idade variando entre 18 e 30 anos, tendo sido divididos em dois grupos: o grupo 1 que respondeu ao questionário de escolha forçada $(n=187$; $51.9 \%$ feminino e $48.1 \%$ masculino), com idade média de 22.4 anos, e o grupo 2 que respondeu ao questionário de mensuração contínua ( $n=191$; $50.8 \%$ feminino e $49.2 \%$ masculino), com idade média de 21.9 anos.

\section{Instrumentos}

Foram desenvolvidos, para este estudo, dois questionários compostos pelos mesmos 20 itens cada. O questionário no formato escolha forçada continha a seguinte instrução: "Leia atentamente e escolha uma das alternativas de cada um dos pares abaixo. Seja o mais sincero possível!", e o questionário no formato de mensuração contínua (no caso, tipo Likert) continha a seguinte instrução: "Leia atentamente as frases abaixo e atribua pontos de 1 a 5, conforme você concorde ou não com as alternativas. Ambas alternativas podem ser pontuadas igualmente. Seja o mais sincero possível!", no qual as respostas variavam entre "não concordo" (1) e "concordo totalmente" (5).

Os 20 itens formulados para ambos os questionários formam 10 pares que investigam diferentes implicações associadas à manifestação do ciúme, subdivididos em quatro diferentes categorias, como pode ser visualizado na tabela 2 .

Tabela 2

Categorias dos itens do questionário

\begin{tabular}{|c|c|}
\hline Categorias & Itens \\
\hline \multirow{3}{*}{$\begin{array}{l}\text { Categoria 1: itens } \\
\text { sobre a influência } \\
\text { do tipo de infide- } \\
\text { lidade }\end{array}$} & $\begin{array}{l}\text { Itens } 1 \text { e } 2 \text { : Sexo leva ao amor; Amor } \\
\text { leva ao sexo }\end{array}$ \\
\hline & $\begin{array}{l}\text { Itens } 5 \text { e } 6 \text { : Sexo implica amar; } \\
\text { Amar implica sexo }\end{array}$ \\
\hline & $\begin{array}{l}\text { Itens } 19 \text { e } 20 \text { : As mulheres procuram } \\
\text { por amor e os homens procuram por } \\
\text { sexo; As mulheres procuram por se- } \\
\text { xo e os homens procuram por amor }\end{array}$ \\
\hline $\begin{array}{l}\text { Categoria } 2 \text { : itens } \\
\text { que visam verificar } \\
\text { a hipótese evolutiva }\end{array}$ & $\begin{array}{l}\text { Itens } 3 \text { e } 4 \text { : Seria pior encontrar } \\
\text { meu parceiro fazendo sexo com } \\
\text { outra pessoa; Seria pior encontrar } \\
\text { meu parceiro dizendo para outra } \\
\text { pessoa que a ama, assim como diz } \\
\text { para mim }\end{array}$ \\
\hline $\begin{array}{l}\text { Categoria } 3: \text { itens } \\
\text { sobre crenças/re- } \\
\text { gras sociais }\end{array}$ & $\begin{array}{l}\text { Itens } 7 \text { e } 8 \text { : Os homens têm liberdade } \\
\text { para demonstrar seus sentimentos; } \\
\text { Os homens não têm liberdade para } \\
\text { demonstrar seus sentimentos }\end{array}$ \\
\hline
\end{tabular}




\begin{tabular}{ll}
\hline \multicolumn{1}{c}{ Categorias } & \multicolumn{1}{c}{ Itens } \\
\hline & $\begin{array}{l}\text { Itens 9 e 10: As mulheres têm liber- } \\
\text { dade para demonstrar suas vontades } \\
\text { sexuais; As mulheres não têm liber- } \\
\text { dade para demonstrar suas vontades } \\
\text { sexuais }\end{array}$ \\
$\begin{array}{l}\text { Categoria 3: itens crenças/re- } \\
\text { gras sociais }\end{array}$ & $\begin{array}{l}\text { Itens 11 e 12: O homem trai mais } \\
\text { que a mulher; A mulher trai mais que } \\
\text { o homem }\end{array}$ \\
& $\begin{array}{l}\text { Itens 13 e 14: Sou uma pessoa } \\
\text { ciumenta; Não sou uma pessoa } \\
\text { ciumenta }\end{array}$ \\
& $\begin{array}{l}\text { Itens 15 e 16: Normalmente meus } \\
\text { parceiros são mais ciumentos que } \\
\text { eu; Normalmente sou mais ciumento } \\
\text { que meus parceiros }\end{array}$ \\
$\begin{array}{l}\text { Categoria 4: itens 17 e 18: As mulheres são } \\
\text { sobre percepção } \\
\text { dos outros e de si }\end{array}$ & $\begin{array}{l}\text { mais ciumentas que os homens; Os } \\
\text { homens são mais ciumentos eu as } \\
\text { mulheres }\end{array}$ \\
\hline
\end{tabular}

Todos os itens foram elaborados a partir de uma revisão da literatura acerca das diferenças entre os sexos em relação ao ciúme. Os itens da Categoria 1 tiveram como objetivo verificar as crenças, de homens e mulheres, a respeito de fatores que apresentam relação direta com ambos os tipos de infidelidade (sexual e emocional); na Categoria 2, os itens objetivavam, a partir da identificação de qual tipo de infidelidade seria pior, sexual ou emocional, testar a hipótese evolutiva de que para homens a sexual seria pior, e para mulheres a emocional (Buss et al., 1992); os itens da Categoria 3 tinham como principal função verificar se homens e mulheres se diferenciam acerca de crenças sociais relacionadas ao relacionamento e infidelidade; e, na Categoria 4, os itens objetivaram verificar se existem ou não diferenças nas concepções, entre homens e mulheres, no que diz respeito à infidelidade no relacionamento amoroso. Especificamente, os itens da Categoria 2 replicam o procedimento proposto por Buss et al., contudo, os itens da Categoria 1 também se aproximam do que foi proposto por esses autores. Já os itens das demais categorias são complementares, tendo sido formulados para o presente estudo.

\section{Procedimentos}

Após aprovação da pesquisa pelo Comitê de Ética, os instrumentos foram aplicados em salas de aula, durante os intervalos, de forma coletiva. Os participantes eram convidados oralmente pelos pesquisadores, e, para aqueles que concordavam em participar, foram entregues as Cartas de Informação e Consentimento Livre e Esclarecido sobre a pesquisa que incluía a permissão para a publicação dos dados em material científico. Cada instrumento constava de instruções próprias, como anteriormente descrito, e pelo menos um pesquisador permaneceu presente na aplicação, minimizando a possibilidade das dúvidas dos participantes não serem respondidas. O tempo para responder os questionários foi de aproximadamente 10 minutos.

Os dados foram analisados a partir do software SPSS versão 13.0 para Windows, valendo salientar que as análises foram realizadas no nível dos itens. O procedimento utilizado para cada um dos grupos foi o teste $t$ de Student, que é adequado para analisar as diferenças entre valores em dois grupos (no caso, feminino e masculino). A partir disso os respectivos effect size ( $d$ de Cohen) foram gerados.

Para que fosse possível visualizar diferenças entre as respostas de homens e mulheres a partir do uso do teste $t$, no teste cujo formato foi de escolha forçada, para cada dupla de itens (1 e 2, 3 e 4 , etc.), o primeiro item corresponderia ao valor "1" e o segundo item da dupla ao valor " 2 ". De modo que, se um maior número de participantes responder com mais frequência ao primeiro item da dupla, então as respostas deste grupo estarão mais próximas de "1", do contrário, mais próximas de “2”. Esse procedimento foi adotado uma vez que os participantes só poderiam escolher um dos dois itens de cada dupla. 


\section{Resultados}

Na tabela 3 são apresentados os resultados de homens e mulheres dos dois grupos (escolha forçada e mensuração contínua), assim como dados descritivos gerais divididos por sexo, com indicações do número de participantes, da média e do desvio padrão em cada item. Estão apresentados na tabela somente as comparações cujo $p$ tenha sido significativo $(p \leq .05)$ e/ou o $d$ tenha sido expressivo $(\geq .20)$.

A partir da tabela 3, considerando os itens de escolha forçada, pode-se verificar que apenas duas duplas de itens, itens 3 (Seria pior encontrar meu/ minha parceiro(a) fazendo sexo com outra pessoa) e 4 (Seria pior encontrar meu/minha parceiro[a] dizendo para outra pessoa que a ama, assim como diz para mim) e 19 (As mulheres procuram por

Tabela 3

Diferenças nas respostas de homens e mulheres em ambos os instrumentos

\begin{tabular}{|c|c|c|c|c|c|c|c|c|}
\hline Itens (tipo do instrumento)* & Gênero & $\mathrm{N}$ & M & $\mathrm{DP}$ & $\mathrm{t}$ & $\mathrm{gl}$ & $\mathrm{p}$ & $\mathrm{D}$ \\
\hline \multirow{2}{*}{ Item 3 (EF) } & M & 89 & 1.39 & .49 & -3.756 & 184 & .001 & \multirow{2}{*}{.56} \\
\hline & $\mathrm{F}$ & 97 & 1.66 & .47 & \multirow{3}{*}{3.299} & \multirow{3}{*}{184} & \multirow{3}{*}{.001} & \\
\hline \multirow{2}{*}{ Item $4(\mathrm{EF})$} & M & 88 & 1.62 & .48 & & & & \multirow{2}{*}{.50} \\
\hline & $\mathrm{F}$ & 95 & 1.38 & .48 & & & & \\
\hline \multirow{2}{*}{ Item $19(\mathrm{EF})$} & M & 89 & 1.07 & .25 & 2.522 & 88.000 & .013 & \multirow{2}{*}{.40} \\
\hline & $\mathrm{F}$ & 95 & 1.00 & .00 & \multirow{3}{*}{-2.522} & \multirow{3}{*}{88.000} & \multirow{3}{*}{.013} & \\
\hline \multirow{2}{*}{ Item $20(\mathrm{EF})$} & M & 89 & 1.93 & .25 & & & & \multirow{2}{*}{.40} \\
\hline & $\mathrm{F}$ & 95 & 2.00 & .00 & & & & \\
\hline \multirow{2}{*}{ Item $01(\mathrm{MC})$} & M & 94 & 2.09 & 1.14 & \multirow{2}{*}{2.178} & \multirow{2}{*}{188} & \multirow{2}{*}{.031} & \multirow{2}{*}{.32} \\
\hline & $\mathrm{F}$ & 96 & 1.75 & .97 & & & & \\
\hline \multirow{2}{*}{ Item 04 (MC) } & M & 94 & 4.14 & 1.22 & \multirow{2}{*}{-3.636} & \multirow{2}{*}{155.008} & \multirow{2}{*}{.001} & \multirow{2}{*}{.54} \\
\hline & $\mathrm{F}$ & 96 & 4.68 & .76 & & & & \\
\hline \multirow{2}{*}{ Item 07 (MC) } & M & 94 & 3.61 & 1.28 & \multirow{2}{*}{-2.165} & \multirow{2}{*}{182.341} & \multirow{2}{*}{.032} & \multirow{2}{*}{.31} \\
\hline & $\mathrm{F}$ & 97 & 3.98 & 1.09 & & & & \\
\hline \multirow{2}{*}{ Item $11(\mathrm{MC})$} & M & 94 & 2.53 & 1.35 & \multirow{2}{*}{2.168} & \multirow{2}{*}{189} & & \\
\hline & $\mathrm{F}$ & 97 & 2.99 & 1.55 & & & .031 & .31 \\
\hline & M & 94 & 2.34 & 1.09 & & & & \\
\hline Item 13 (MC) & $\mathrm{F}$ & 97 & 3.14 & 1.19 & -4.838 & 189 & .001 & .70 \\
\hline & $\mathrm{M}$ & 93 & 2.41 & 1.52 & & & & \\
\hline Item 14 (MC) & $\mathrm{F}$ & 97 & 1.90 & 1.23 & 2.532 & 177.057 & .012 & .37 \\
\hline & M & 93 & 3.09 & 1.34 & & & & \\
\hline Item $15(\mathrm{MC})$ & $\mathrm{F}$ & 97 & 2.74 & 1.35 & 1.756 & 188 & .081 & .26 \\
\hline Ltom $1 \mathrm{MCC}$ & M & 93 & 1.77 & 1.00 & 2600 & 170265 & 001 & 50 \\
\hline ltem 10 (MC) & $\mathrm{F}$ & 97 & 2.39 & 1.32 & -3.030 & $1 / 8.205$ & .001 & .52 \\
\hline
\end{tabular}

* EF: escolha forçada; MC: mensuração continua. 
amor e os homens procuram por sexo) e 20 (As mulheres procuram por sexo e os homens procuram por amor), mostraram significância estatística, com efeito variando entre .40 e .56 , o que pode ser considerada como uma diferença moderada. Contudo, na dupla 19 e 20, apesar da diferença significativa e efeito expressivo, ambos os grupos (homens e mulheres) apresentaram um índice de respostas mais alto para o item 20 (de fato, 100\% das mulheres responderam neste item, e $96.5 \%$ dos homens também).

Na mesma tabela, também verifica-se que oito itens no modelo de mensuração contínua apresentaram significância estatística, quais sejam, item 1 (Sexo leva ao amor), item 4 (Seria pior encontrar meu/minha parceiro(a) dizendo para outra pessoa que a ama, assim como diz para mim), item 7 (Os homens têm liberdade para demonstrar seus sentimentos), item 11 (O homem trai mais que a mulher), item 13 (Sou uma pessoa ciumenta), item 14 (Não sou uma pessoa ciumenta), item 15 (Normalmente meus parceiros são mais ciumentos que eu), e item 16 (Normalmente sou mais ciumento que meus parceiros). Ressalta-se que a maioria dos efeitos foi superior a .30 , indicando diferença moderada entre os grupos, com exceção ao item 15 , que apresentou diferença pequena.

\section{Discussão}

A discussão dos resultados será feita em dois momentos. No primeiro, os dados serão discutidos de acordo com as categorias de itens apresentadas no método e, no segundo, será feita uma discussão mais ampla acerca dos resultados. No que se refere à Categoria 1 (itens que identificam crenças sobre a influência do tipo de infidelidade), nos itens $1 \mathrm{e}$ 2 , que visavam verificar o entendimento acerca de qual variável (sexo ou amor) levaria à outra, não houve diferenças significativas em ambos os questionários, sugerindo que homens e mulheres entendem que o amor leva ao sexo, mais do que o contrário. Do mesmo modo, nos itens 5 e 6, que tinham função similar aos itens 1 e 2, verificou-se que, para homens e mulheres, nas duas versões do instrumento, amor implica mais em sexo, e não o contrário. E, nos itens 19 e 20, cuja função era verificar as crenças sobre o que cada gênero entende que homens e mulheres buscam em um relacionamento, os resultados sugerem que, para ambos os sexos, nas duas versões do instrumento, as mulheres procuram por amor e os homens por sexo.

Se de um lado, os resultados encontrados nesta categoria estão de acordo com os resultados apresentados por Harris e Christenfelf (1996b), de que para homens e mulheres a infidelidade emocional deve implicar mais na sexual do que o contrário. Ainda assim, ambos os sexos apresentam a crença de que as mulheres estão mais ligadas ao amor, e os homens mais ligados ao sexo. Esta diferença nas crenças sociais a respeito da busca de homens e mulheres em um relacionamento deve estar ligada, provavelmente, a comportamentos socialmente esperados para os sexos, que diferem nas sociedades ocidentais, e não à diferença inata entre a mulher e o homem (Harris, 2003; Harris \& Christenfeld, 1996a). Em síntese, em ambas as versões do instrumento não foram encontradas diferenças entre os sexos no que diz respeito as variáveis, sexo e amor, enquanto influenciadoras na infidelidade, o que vai contra os dados apresentados pelos estudos com escolha forçada de um modo geral (Buss et al., 1992, 1996; Shackelford et al., 2002), isto é, não corroborando a hipótese DS, mas sim a JSIM.

Já no que se refere à Categoria 2 (itens que visam verificar a hipótese evolutiva), representada por apenas um par de itens (3 e 4), a partir do instrumento de escolha forçada, foi verificada a clássica diferença entre os sexos (Buss et al., 1992). Contudo, na versão de mensuração contínua, homens e mulheres apresentaram respostas que sugerem que ambos os sexos são perturbados por ambos os tipos de infidelidade, o que corrobora os pressupostos sócio-cognitivos da diferença entre os sexos (DeSteno \& Salovey, 1996; Harris, 2003a; Harris, 2005). Como aponta Harris (2005), o instrumento 
de escolha forçada apresenta vieses importantes em seus resultados, inicialmente por não permitir que o participante opte em termos de intensidade e na escolha de ambas opções, e também por sofrer influências culturais e ideográficas que podem resultar em alterações importantes nos resultados obtidos.

$\mathrm{Na}$ continuidade (Categoria 3: itens sobre crenças/regras sociais), os resultados encontrados nos itens 7 e 8 sugerem que, tanto homens como mulheres, em ambos instrumentos, acreditam que os homens têm liberdade para demonstrar seus sentimentos, e, do mesmo modo, os resultados dos itens 9 e 10, nas duas versões do questionário, sugerem que ambos os sexos acreditam que as mulheres têm liberdade para demonstrar seus desejos ou preferências quando se trata de sexo. Por fim, nos itens 11 e 12, os resultados, nas duas versões do instrumento, mostraram que homens e mulheres acreditam que o homem trai mais que a mulher.

Os dados encontrados nos itens da Categoria 3 apontam que homens e mulheres apresentam crenças similares a respeito das possibilidades sociais, de ambos os sexos, no que se refere ao relacionamento (liberdade sexual e sentimental). Esta similaridade no pensamento entre homens e mulheres parece se refletir em outros resultados, sobretudo quando os gêneros não manifestam diferenças no tipo de infidelidade que os perturba, como por exemplo, nos resultados encontrados em um estudo realizado por Harris (2003a), no qual ambos os sexos apresentaram mais ciúme sexual, ou ainda, no estudo de Harris e Christenfeld (1996a), no qual ambos os sexos entendiam que a infidelidade emocional implicava na sexual. Similarmente às categorias anteriores, os dados suportam a hipótese JSIM, mas não a DS. E, na Categoria 4, com itens sobre a concepção dos outros e de si em relacionamentos amorosos, nos itens 13 e 14, verificou-se que ambos os sexos apresentaram um equilíbrio entre considerar-se como ciumento ou não dentro de um relacionamento amoroso. Contudo, nos itens 15 e 16, homens e mulheres tenderam a considerar o parceiro como mais ciumento, sobretudo os homens. Por fim, verificou-se que nos itens 17 e 18 , tanto os homens como as mulheres, em ambos instrumentos, consideraram as mulheres como mais ciumentas do que os homens - dado que corrobora resultados de estudos anteriores (Buss et al., 1992; Mullen \& Martin, 1994). Talvez a crença de que o homem traia mais do que a mulher seja uma das variáveis importantes para o ciúme mais intenso nas mulheres. Entretanto, é relevante também considerar que também neste estudo, ambos os sexos tenderam a perceber seus parceiros como mais ciumentos no relacionamento amoroso, não demonstrando diferenças expressivas entre os sexos, tal qual preconizado pela hipótese JSIM.

Em uma perspectiva mais ampla de discussão, os dados encontrados neste estudo evidenciaram dois aspectos principais acerca do ciúme: que homens e mulheres descrevem crenças semelhantes sobre infidelidade e respondem diferentemente quando o instrumento utilizado é o formato escolha forçada. Os resultados estão de acordo com o que têm postulado os teóricos da teoria sócio-cognitiva, tanto no que se refere a pouca variabilidade nas crenças relacionadas à infidelidade, quanto à limitação do instrumento de escolha forçada.

Portanto, pode-se concordar com Harris (2005) a respeito de ser esperado que o desencadeador e a manifestação das reações de ciúme não se diferenciem entre os gêneros, mas sim entre os indivíduos, uma vez que cada indivíduo terá crenças idiossincráticas. Cabendo acrescentar que as crenças não seriam os únicos fatores a exercer influência sobre a escolha do tipo de infidelidade entre homens e mulheres. Na verdade, em última instância sempre é necessário identificar variáveis da história de cada indivíduo para entender ocorrência de ciúme (Costa, 2005).

Um dado que ainda merece ser comentado refere-se à refutação da hipótese da DS (para a mulher, o ciúme emocional aparece significantemente mais intenso e, para o homem, o ciúme sexual e o ciúme amoroso perturbam com intensidade similar). Como verificado no estudo de Harris e Christenfeld 
(1996a), também no presente estudo, ambos os sexos parecem acreditar que o amor leva ao sexo, mais do que o inverso, assim como apresentam uma tendência a relacionar sexo aos homens e o amor às mulheres.

\section{Considerações finais}

Ainda que se considere que os resultados deste estudo tenham contemplado os objetivos, algumas limitações devem ser traçadas. Em relação com amostra, deve-se notar que houve uma restrição a estudantes universitários de apenas uma instituição de ensino superior. Além disso, as análises não levaram em conta qualquer controle em relação ao status de relacionamento dos participantes. No futuro, novas pesquisas devem ser realizadas, com amostras de casais e considerando variáveis tais como estar ou não em um relacionamento estável, tempo de relacionamento, satisfação com o relacionamento. Outro aspecto que é o instrumento utilizado foi desenvolvido exclusivamente para este estudo, sendo que deve ser utilizado em outras amostras buscando verificar sua aplicabilidade.

Portanto, os resultados da presente pesquisa evidenciaram que tanto aspectos da proposição evolutiva quanto da sócio-cognitiva foram encontrados, ainda que necessitem de aprofundamento, pois como argumentou Ades (2003), embora diferenças entre os sexos possam ser identificadas, estas não são evidentes em todos os aspectos relacionados ao ciúme, o que leva a supor que sofrem influência do contexto. Dada a importância de estudos que visem a compreensão das diferenças e similaridades entre os sexos, uma vez que tal compreensão pode possibilitar um maior entendimento acerca das relações entre casais, futuras pesquisas devem ter como proposta ampliar o leque abordado neste trabalho.

\section{Referências}

Ades, C. (2003). Gender differences in the romantic jealousy of Brazilian young adults. Estudos:
Revista da Universidade Católica de Goiânia, 30, 1175-1188.

Buss, D. M., Larsen, R. J., Westen, D., \& Semmelronth, J. (1992). Sex differences in jealousy: Evolution, physiology, and psychology. Psychological Science, 4, 251-255. doi: 10.1111/ j.1467-9280.1992.tb00038.x

Buss, D. M., Larsen, R. J., \& Westen, D. (1996). Sex Differences in jealousy: Not gone, not forgotten, and not explained by alternative hypotheses. Psychological Science, 6, 373-375. doi: 10.1111/j.1467-9280.1996.tb00392.x

Costa, N. (2002). Terapia analítico-comportamental: dos fundamentos filosóficos à relação com o modelo cognitivista. Santo André: ESETec Editores Associados.

Costa, N. (2005). Contribuições da psicologia evolutiva e da análise do comportamento acerca do ciúme. Revista Brasileira de Terapia Comportamental e Cognitiva, VII, 1, 5-13.

DeSteno, D. A. \& Salovey, P. (1996). Evolutionary origins of sex differences in jealousy?: Questioning the "fitness" of the model. Psychological Science, 7(6), 367-372. doi: 10.1111/j.14679280.1996.tb00391.x

DeSteno, D., Bartlett, M. Y., Braverman, J., \& Salovey, P. (2002). Sex differences in jealousy: Evolutionary mechanism or artifact of measurement? Journal of Personality and Social Psychology, 83(5), 1103-1116. doi:10.1037//00223514.83.5.1103

Harris, C. R. (2002). Sexual and romantic jealousy in heterosexual and homosexual adults. Psychological Science, 13(1), 13-17.

Harris, C. R. (2003a). Factors associated with jealousy over real and imagined infidelity: An examination of the social-cognitive and evolutionary psychology perspectives. Psychology of Women Quarterly, 27, 319-329. doi: 10.1111/1471-6402.00112

Harris, C. R. (2003b). A review of sex differences in sexual jealousy, including self-report data, psychophysiological responses, interpersonal 
violence, and morbid jealousy. Personality and Social Psychology Review, 7(2), 102-128. doi: 10.1207/S15327957PSPR0702_102-128

Harris, C. R. (2004). The evolution of jealousy. American Scientist, 92, 62-71.

Harris, C. R. (2005). Male and female jealousy, still more similar than different: Replay to Sagarin (2005). Personality and Social Psychology Review, 9(1), 76-86. doi:10.1207/s15327957pspr0901_6

Harris, C. R. \& Chtistenfeld, N. (1996a). Gender, jealousy, and reason. Psychological Science, 7 (6), 364-366. doi: 10.1111/j.1467-9280.1996. tb00390.x

Harris, C. R. \& Chtistenfeld, N. (1996b). Jealousy and rational responses to infidelity across gender and culture. Psychological Science, 7(6), 378379. doi: 10.1111/j.1467-9280.1996.tb00394.x

Kingham, M. \& Gordon, H. (2004). Aspects of morbid jealousy. Advances in Psychiatric Treatment, 3, 207-215. doi: 10.1192/apt.10.3.207

Leite, S. M. C. S. (2001). Ciúme e inveja: A visão comportamental. Em R. C. Wielenska (Org.), Sobre comportamento e cognição questionando e ampliando a teoria e as intervenções clínicas e em outros contextos (vol. 6, pp. 70-73). Santo André: ESETec Editores Associados.

Mullen, P. E. \& Martin, J. (1994). Jealousy: A community study. British Journal of Psychiatry, 164, 35-43.

Ramos, A. L. M. \& Calegaro, M. (2001). Resenha: A paixão perigosa: Por que o ciúme é tão necessário quanto o amor e o sexo. Psicologia: Teoria e Pesquisa, 17(3), 293-295. doi: 10.1590/ S0102-37722001000300012

Sagarin, B. J. (2005). Reconsidering evolved sex differences in jealousy: Comment on Harris. Personality and Social Psychology Review, 9(1) 62-75. doi: 10.1207/s15327957pspr0901_5

Sagarin, B. J. \& Guadagno, R. E. (2004). Sex differences in the contexts of extreme jealousy. Personal Relationships, 11, 319-328. doi: 10.1111/j.14756811.2004.00085.x

Shackelford, T. K, Buss, D. M. \& Bennett, K. (2002). Forgiveness or breakup: Sex differences in responses to a partner's infidelity. Cognition and Emotion, 16(2), 299-307. doi: 10.1080/02699930143000202

\section{Data de recepção: 08 de dezembro de 2014 Data de aceitação: 24 de junho de 2015}


